\title{
Comprehensive Opportunity and Lost Opportunity Control Model and Enterprise Risk Management
}

\author{
Akira Nishimura $^{1}$ \\ ${ }^{1}$ Faculty of International Business Management, Beppu University, Japan \\ Correspondence: Akira Nishimura, Faculty of International Business Management, Beppu University, 7-18-8 \\ Miwadai Higashi Fukuoka, 811-0212, Japan. Tel: 81-092-608-8011. E-mail: ZTD03361@nifty.com
}

Received: May 26, 2015

Accepted: June 24, 2015

Online Published: July 22, 2015

doi:10.5539/ijbm.v10n8p73

URL: http://dx.doi.org/10.5539/ijbm.v10n8p73

\begin{abstract}
The purpose of this paper is to build a comprehensive opportunity and lost opportunity control model through which contemporary management accounting can act in alignment with enterprise risk management, as well as to examine its managerial and socio-economic functions in relation to risk management in the context of uncertainty in a global finance-oriented society. For this purpose, the paper demonstrates the structure and characteristics of this model specifically in contrast with traditional and other control models that have been previously addressed for controlling the changes and diversity of business environments. We can recognize from this demonstration that the accounting control system based on opportunity and lost opportunity control model has shifted its fundamental focus from feedback systems, profitability, and managerial control to feed-forward, value creation, and enterprise governance. The paper also refers to the socio-economic function that the model fulfills in the disclosure and transparency of the risk management process. These results lead to the conclusion that contemporary management accounting expands its short-term efficiency and company-centered effectiveness into long-term efficiency and social effectiveness.
\end{abstract}

Keywords: profit opportunity, risk, opportunity, lost opportunity, risk management report

\section{Introduction}

As global competition leads to a changeable and diverse economic environment where technological innovation accelerates and consumer needs rapidly change, enterprises must always consider uncertainty when planning business strategies. Measurement and control of uncertainty is a critical problem for contemporary business management. Value creation in enterprises, in particular, is strongly influenced by financial uncertainty. Uncertainty stems not only from environmental complexity and diversity but also from the information and control level of management. In a global, finance-oriented economy, accounting as an information system also plays an important part in controlling uncertainty, in conjunction with the judgment and experience of senior managers.

In examples such as the Enron bankruptcy in December 2001 and the collapse of the WorldCom group in July 2002, charismatic senior managers who had previously been considered independent of financial oligarchies and shareholder influence (Berle \& Means, 1932) had stained their hands with financial manipulation and related financial instruments (derivatives), sacrificing long-term value for short-term profits (Richardson, 2009, 2010). This resulted in a dramatic rise in uncertainty in the international economy. At the same time, it was found that window-dressing accounts that had concealed their dangerous business results were created in conspiracy with certified public accountants, adding further fuel to the fire (Stuart \& Stuart, 2004). Moreover, as the production structure and lifestyle in some capitalistic economies became more finance-oriented, some senior managers in global businesses became arrogant (Collins, 2009) and lost sight of true profit opportunities, instead treading a path toward failure by keeping step with Lehman Brothers in 2008 (Ingrassia, 2011). These events shook the financial and monetary base not only in the US but also some European economies (Richardson, 2009). The bankruptcy of automobile companies such as GM and Chrysler in 2009, the long-running depression in Europe, and Japan's "two lost decades" show the serious nature of current uncertainty in the global finance- and information-oriented society.

Enterprises should wrestle with such uncertainty for stable and durable business growth and, as a matter of social responsibility, give an account of its management to stakeholders including investors; such management not only 
influences corporate destiny (potentially including bankruptcy) but can also decrease social uncertainty or economic stagnation. At present companies tend to balance short-term competitive strategy with a long-term growth strategy to create business value for sustainable business growth (Nishimura, 2007). To effectively and synthetically control opportunity and risk that connect closely to business-value creation strategies under uncertainty, enterprises should establish effective and efficient management systems to find and exploit opportunities (hereinafter "profit opportunities" when clarifying the relation with accounting profit and risk) and correspondently mitigate risk that is deeply related to control of uncertainty. They should furthermore strengthen mutual understanding with stakeholders and society about enterprise governance through transparent and trustworthy disclosure of risk management processes to maintain sustainable growth and dispel social uncertainty (Nishimura, 2006; IFA, 2004).

This raises the question of how management accounting wrestles with risk and what control models accountants should build for risk management and its social application. Unfortunately, accounting control systems have not so far included risk and profit opportunity information in their control models, comprehensively controlled risks related to uncertainty, or given stakeholders a clear account of management processes for discharging accountability and controllability. Therefore, this paper builds a feed-forward accounting control system based on opportunity and lost opportunity and examines contemporary management accounting from the comprehensive perspective of enterprise risk management to clarify needed structural changes and future directions.

\section{Basic Framework of the Accounting Control System}

Before discussing the role of accounting control systems in enterprise risk management, we should clarify the relation between accounting income and profit opportunities and risks. As COSO (2004) points out, "uncertainty presents both risk and opportunity, with the potential to erode or enhance value" (p. 3). Therefore, risk and opportunity must be holistically (Note 1) managed with business strategy as an axis of business value management. Note that here "opportunity" refers to profit opportunity in a qualified sense, since enterprises aim at finding and exploiting opportunities that lead to accounting profit, not opportunities in general, and simultaneously have an internal and external relation to risk (Nishimura, 2012, 2015). Thus, profit opportunity is recognized as opportunity with a certain objective and subjective probability that is transformed into accounting profit in the near future (Nishimura, 2011), in the same way as risk, or the possibility of a disappointing result (accounting loss) under the condition. Risk in a quantitative sense is considered as expected loss, which can be calculated by multiplying the likelihood of the event by the total loss experienced when the event occurs (Smith \& Merritt, 2002).

Risk management is also considered enterprise risk management, rather than management of risk in general (Nishimura, 2015). The result is that like "profit opportunity", it is dealt with as part of enterprise governance for ensuring sustainable value creation; risk management follows profit opportunity management as a comprehensive form of enterprise risk management. In traditional management accounting, enterprises have focused mainly on accounting income and used this information to plan for and control business activities. However, in order to meet profit targets under uncertain conditions, management should be proactive in the process by which profit is created, not just in its result. Management accounting not only yields feedback on variance information to planning process in the following accounting year, but must also proactively find and exploit profit opportunity and control risk for optimum value actualization. Therefore, management accounting should also measure profit opportunities and risks to fulfill its function in proactive strategic decision-making and evaluate the results of proactive countermeasures against risks and opportunity exploitation in the process of transforming profit opportunity/risk into accounting income.

As indicated in Figure 1, business processes that ultimately result in profit or loss are composed of many strategic and managerial activities that involve profit opportunity and risk (COSO, 2004; Schneier \& Miccolis, 1998). Accounting profit results not only from positive value creation management, which aims to maximize profit opportunities and minimize lost opportunity, but also from risk management, which seeks to avoid or minimize events that may preclude profit opportunities or value creation. Although loss is traditionally recognized in an accounting book when an enterprise does not succeed in actualizing its plans, lost profit opportunity or opportunity cost that dilutes business value in the working process of these plans is not accounted for. Under strong uncertainty, it is important that accounting control systems take a new approach to the comprehensive recognition of opportunity and lost opportunity to create business value as planned. Enterprise risk management and accounting control systems use different approaches to realizing the common goal of maximizing business value (Holmquist, 2012). As Rasid, Isa, and Ismail (2014) point out, "In fact, risk management and management accounting are integral to strategic planning and performance assessment" (Grote, 
2014, p. 132). If managers incorrectly control for risks, profit opportunity can instead transform into lost opportunity (see Figure. 1). Therefore, successful strategy implementation requires that risk management is carried out in parallel with profit opportunity management. Enterprises should proactively measure and control risks for profit management in feed-forward accounting control systems. Therefore, strategic-level enterprise risk management acquires a more important role than low-level management, which is focused on downside risks and risk avoidance, because it "incorporates a focus that goes beyond addressing downside risks to a strong focus on upside risks-an offensive strategy of identifying and seizing opportunities" (Arnold, Benford, Canada, \& Sutton, 2011, p. 174). As risk management is closely connected with whole activities from strategic planning to management and

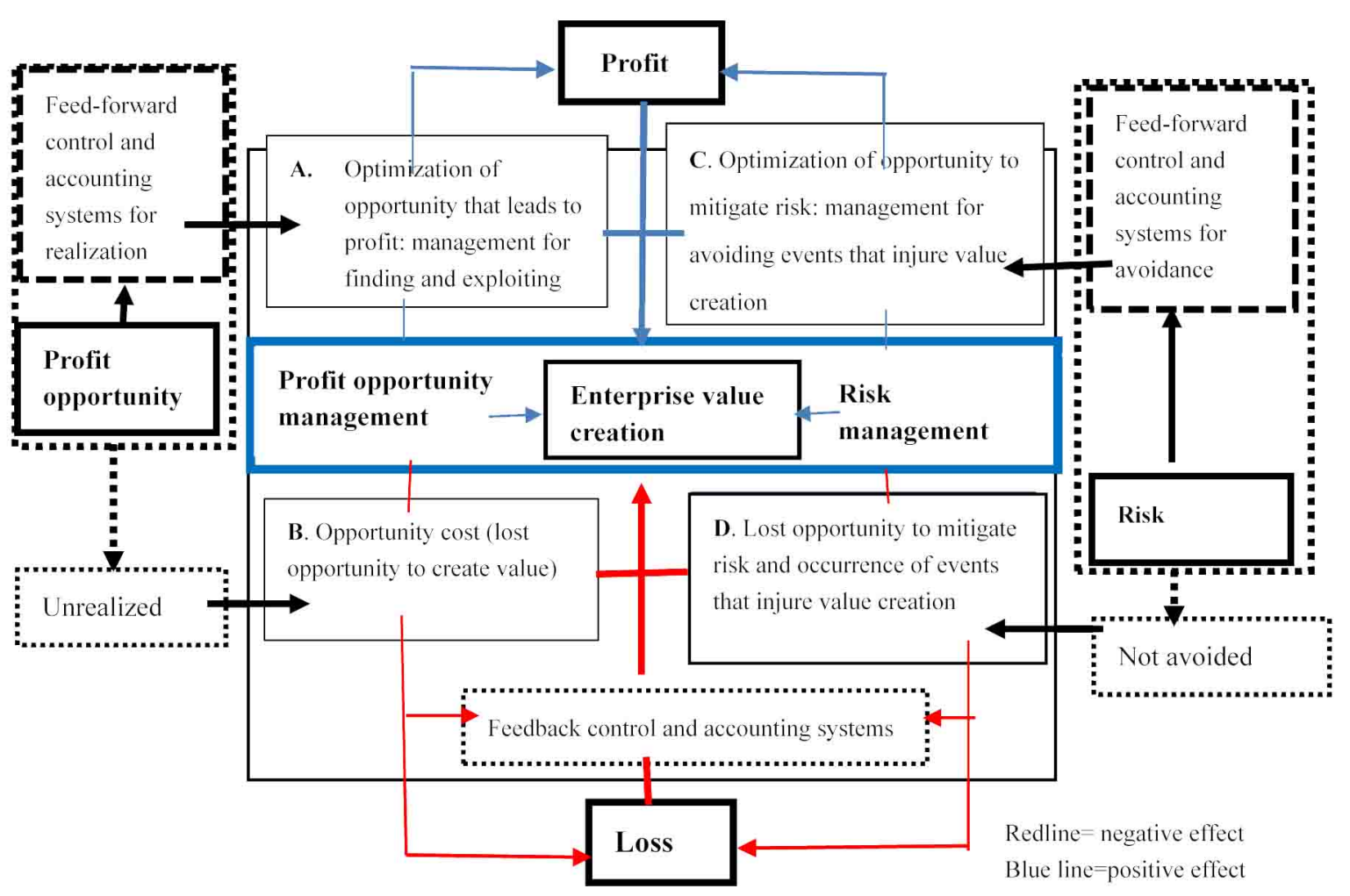

Figure 1. Transformation process of profit opportunity and risk into accounting profit and loss

operational controls, an accounting control system as a feed-forward form of management accounting must also comprise comprehensive and enterprise-wide risk information in its daily measurement and evaluation (Shank \& Miguel, 2009; Seal, 2006; Schneier \& Miccolis, 1998). Because accounting is conceptually structured around the concept of profit, and profit opportunity and risk too embody future information related to this concept, feed-forward accounting control systems must also be constructed on this fundamental concept and its future-oriented information. Thus, when comprehensively implementing enterprise risk management, enterprises should plan for and control management activities from the aspect of opportunity and lost opportunity, not of past profit and loss, and should build a new comprehensive opportunity and lost opportunity control (COLC) model. Figure 1 indicates that enterprises must pay attention to measurement and evaluation of opportunity and lost opportunity for business value creation.

\section{Development of Accounting Control Systems}

Uncertainty has influenced the mode of management accounting as well as business management (Knight, 1921), and recently its influence was clarified in risk management. Uncertainty represents objectively and subjectively unstable conditions for beginning an action without complete information, or "an unknown probability of occurrence of an event" (Jaafari, 2001, p. 101). In contrast, risk represents the probability of a disappointing result under this condition. Enterprises can take some countermeasures against risk (e.g., buying insurance), unlike threat and unrest under uncertainty, and so have tried to develop risk management and risk-related accounting control systems to mitigate uncertainty (Nishimura, 2011). Accounting control systems founded on 
globally finance-oriented and competitive economies have had to control uncertainty more sensibly and commit more deeply to risk management than before. In the following subsections, we further explore the state of accounting control systems that enterprises and researchers have devised to address changes and diversity in uncertainty. We describe it in the development process from the traditional accounting control system to Demski's ex post model and cost design. We then focus on COLC model to define the functions of contemporary management accounting in enterprise risk management.

\subsection{Traditional Accounting Control System}

In relation to diversity and complexity, the traditional accounting control system does not include "all inputs to the decision model" (Demski, 1967, p. 701), instead consistently using a first-formed plan as a target and an evaluation basis for actual value, despite a changeable environment. They cannot give any control direction to management beforehand in relation to change of environmental factors, and deviation between planned and observed values cannot display all changes of environmental factors or give variance information for interim performance evaluations, since this is due to a static model like the following:

\begin{tabular}{|c|}
\hline Forecast (standard) $\quad$ Observed $\quad$ Deviation \\
\hline Budget profit - Actual profit $=$ Profit variance \\
$100-80=20(\mathrm{U})$ \\
Standard cost - Actual cost $=$ Cost variance
\end{tabular}

Note. The above numerical values are hypothetical; $\mathrm{U}=$ Unfavorable variance.

Enterprises can analyze profit or cost variance as price variance and volume (or hour) variance only after the fact and provide them as information feedback for next-period budget profit and standard cost. Because they have no "optimum adjustment to changed conditions", the traditional accounting control system cannot "gauge significance by determining the opportunities foregone as a result of deviation and failure to respond to it" (Demski, 1977, p. 233). No proactive and preventive control information is provided. In this sense, such system is not conscious of irremediable changes and diversity.

Accounting control systems are intrinsically founded on bookkeeping, with duties consisting of recording journal entries in various journals, posting them in ledgers, and preparing a trial balance. Therefore, while the traditional system can inform planning processes for the next accounting year of variances between plans and actual results, it cannot do so within the current year because of its "planning-control dichotomy" (Demski, 1977, p. 233). In this paper, feedback and feed-forward strictly refer to the control function of variance analysis in the current accounting year. In this sense, the traditional accounting control system fulfills a cognitive function in this variance analysis for the next period control, but cannot make opportunity cost clear for want of optimum thought.

\subsection{Demski's Model: Ex Post System}

Considering feedback thought in the action of variance analysis to optimum profit planning, Demski developed a unique accounting control system based on the viewpoint of opportunity and opportunity cost - the ex post system. This system inputs all information to the model and calculates optimum profit after the fact using a liner programming method to recognize various changes in environmental factors and to clarify profit forecast variance (opportunity) and opportunity cost. This model allows recognizing opportunity cost variance through comparing optimum (ex post) profit with actual profit in the current period (Nishimura, 2003). Forecast profit (opportunity) variance is measured by comparing ex ante profit at the forecast stage with ex post profit at the actual evaluation stage. These two variances make it possible to measure managers' forecast ability to the optimum profit and maladjustment of corporate resources to optimum usage. It also allows for model revision in the following period (Demski 1967; 1977). This model also has a feedback function for opportunity cost variance, as shown in the following formulation: 


\begin{tabular}{|llll|}
\hline \multicolumn{3}{|c|}{ Feedback accounting control process } \\
\hline Forecast & Target & The observed & \multicolumn{1}{c|}{ Deviation } \\
\hline Ex ante profit & - Ex post profit & $=$ Forecast profit variance \\
100 & $-120 \downarrow(2 \mathrm{nd})$ & $(1 \mathrm{st})$ & $=-20(\mathrm{~F})$ \\
& Ex post profit - Actual profit & $=$ Opportunity cost variance \\
& 120 & -80 & $=40(\mathrm{U})$ \\
\hline & $(100-120)+(120-80)=-20+40=20(\mathrm{U})$ \\
\hline
\end{tabular}

Note. $\mathrm{F}=$ Favorable variance

This ex post accounting system assumes (1) application of some well-defined formation in the planning process, (2) management ability to distinguish between avoidable and unavoidable variances or deviations, (3) the usefulness of feedback control information, and (4) limitations on searching for possible opportunities (Demski, 1967, p. 702). In this case, ex ante and ex post profits are structured as optimum profit by using linear programming that includes various data or variable inputs (contribution margin, production volume of products, limited resources, per-unit production requirements, and so on) in the profit-maximization model, and ex post profit is calculated under the same conditions as observed profit at the end of the accounting period. This accounting control system can thus measure environmental change and diversity to indicate "the efficiency of the planning process" and "the need for additional forecasting efforts" through deviation between ex ante and ex post profits, and indicates "the opportunity cost of non-optimal capacity utilization" with opportunity cost variance (Demski, 1967, pp. 704-711; see also Demski, 1969) This variance analysis facilitates learning and remedial action in wide-ranging aspects of the planning and control process because of the linear programming structured in the system. This accounting control system carries out feedback control functions for variance cognition in the current accounting year and for control in the next. This cognitive function is qualitatively more advanced in specifying opportunity cost and opportunity than the traditional accounting control system.

\subsection{Cost Design and the Feed-forward Control Model}

Unfortunately, in the ex post system, although the variances give significant indicators to management, they cannot be connected with the revision of forecast process in the current accounting year on account of feedback system, so learning and revision in the intra-period is controversial (see Cushing, 1968; Demski, 1968). Thus, an accounting control system that can fulfill its function for proactive measurement and evaluation of planning and controlling process should include feed-forward control information in plural ex ante profits. That is, feed-forward thought must be adopted in the model, not only with regards to information. Incidentally, the term "feed-forward" can be defined as the following meaning: before executing a plan, a manager has information on factors or conditions that will disturb its realization, and adopts some proactive methods to alter and improve them, in contrast to "feedback" in which the manager reflects on actual results and carries out reactive action to get close to the expected target. We can see this in cost designs that Japanese automobile companies developed and practiced in the 1970s, referred to as target costing in English, where cost design tends to include all competitive strategic information based on value (relative relation between function and cost) in the model and determines target cost as an evaluation standard through cost variance analysis. This target cost is extracted through comparing two planned costs (allowable cost and estimated cost or piling up cost) and considering prior cost improvement that the prior cost variance urges management to do.

As shown in the following formulation, cost design as well as COLC model described is feed-forward, since it integrates prior cost variance with a competitive strategic plan (estimated cost) beforehand to search for target cost through proactive improvement and to evaluate performance from opportunity and opportunity cost.

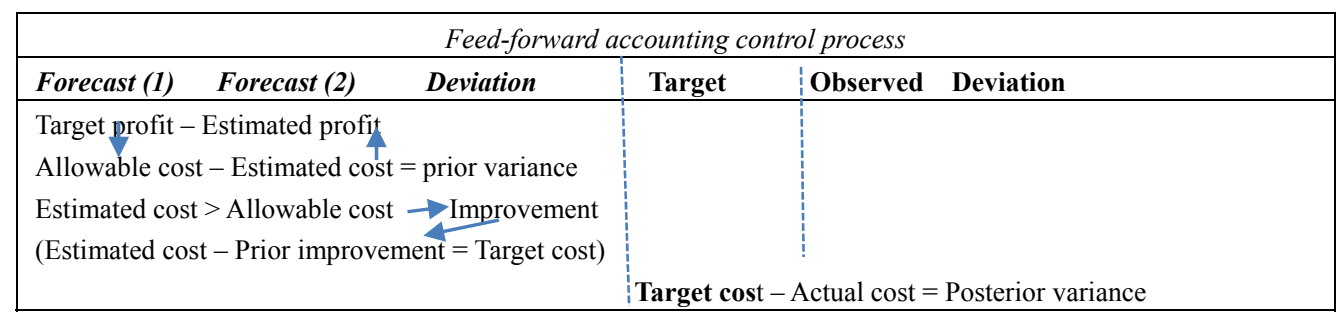

Note. Forecast (1) = Primary long-term plan; Forecast $(2)=$ Secondary competitive plan. 
Target profit is defined as the planned profit that must be achieved in the total life cycle of a designed product and leads to allowable cost in one period or per one product, while estimated profit is calculated on the basis of estimated cost that is decided by piling up improved functions and costs on an existing product cost similar to the designed product from the viewpoint of competitive strategy (Tanaka, 1992). Allowable cost must also be realized in the life cycle of the product to attain the target profit. Therefore, prior cost variance is a proactive indicator with which cost should be improved beforehand. Target cost that is calculated after considering estimated cost and prior cost improvement works as the strategically optimum evaluation standard to actual cost as well as posterior cost improvement targets. As a result, posterior cost variance also means opportunity cost or profit opportunity forgone, in which organizational ability and resources cannot achieve the optimal cost for competitive strategy, although it feeds back to the planning process in the next accounting year.

This feed-forward accounting control system aims to forecast profit opportunity (or opportunity to mitigate risk) from sustainable growth and competitive strategy and fix target cost through prior and intra-period improvement, and to evaluate performance in terms of the attachment degree of the target (optimal strategic target). Performance is evaluated by the attainable capacity standard for competitive strategy. As a result, this system, which includes all information on function, quality and cost in the two optimal cost models in the long-term growth strategy and the short-term competitive strategy, intends to cope with changes and diversity in business environments for the actualization of profit opportunity maximization and risk minimization of a product; the integration of high quality and low cost by means of just-in-time systems, zero inventory, and total quality control. Although cost design thinks much of such a risk control method as zero inventory, it as well as the ex post system does not refer to opportunity to mitigate risk and lost opportunity (C and D in Figure 1) in accounting control system, apart from recognizing opportunity and opportunity cost related to profit opportunity (A and B in Figure 1)

When comparing this variance analysis with that of ex post system, we find one fundamental difference. Although the ex post system makes opportunity cost variance clear, variances explain profit variance in the traditional accounting system in details from the viewpoint of opportunity and opportunity cost. The evaluation of actual profit after the fact is regarded as more important than the prior decision of optimum target.

So in the traditional system profit variance $=$ budget profit - actual profit, while in ex post systems, profit variance $=$ forecast profit variance + opportunity cost variance $=($ ex ante profit - ex post profit $)+($ ex post profit - actual profit).

In contrast, cost variance analysis in cost design does not divide traditional cost variance into parts, but rather gives variance analysis a new meaning for deciding target cost decision, because it newly draws out two peculiar variances or indicators for prior and posterior cost improvement, and gives management an optimal target as an inter-period standard for control by using the former improvement (variance) and as an evaluation standard to actual cost through the posterior cost variance for competitive strategy. Of course, posterior variance feedback to the planning process is for the next accounting year. Logically, cost design can also adopt linear programming for deciding optimal cost and practically use some well-defined formulations for applications such as industrial engineering, value engineering, quality management, or design review to lead to a strategically fittest cost (Tanaka, 1985, 1995). This new idea is founded on a feed-forward control system. However, this system focuses mainly on target cost for cost management based on opportunity and opportunity cost thought, even while connecting with profit planning. As stated at the beginning, as actual business environments have recently experienced increased changes and diversity (uncertainty), risk management has become increasingly important for the whole of business activity. All enterprises should wrestle with this uncertainty and look for more future-oriented and comprehensive target information (comprehensive opportunities, opportunity cost, and lost opportunity from A to D in Figure 1) beyond target cost (opportunity and opportunity cost in A and B) in order to effectively carry out enterprise risk management and governance. Management accounting tends to emphasize risk information over cost (Soin \& Collier, 2013).

\section{Comprehensive Opportunity and Lost Opportunity Control (COLC) Model}

\subsection{Structure and Characteristics}

Enterprises should effectively manage profit opportunity and risk for dispelling uncertainty and maintaining long-term business growth, while conforming to corporate governance regulations. For this purpose, they should incorporate comprehensive feed-forward control information into models and carry out profit opportunity and risk management beyond profit and cost management. The feed-forward accounting control system that is founded on COLC model intends to recognize and control profit opportunity and risk from a long-term viewpoint for sustainable growth strategies, and short-term viewpoints for immediate competitive strategy. It 
uses variances in these profit opportunities and risks to search for optimal target profit for the control of business activities and the evaluation of actual profit.

Concretely, variances between forecast and estimated profit opportunities or risks lead to forecast profit opportunity or risk variance. On the basis of these variances, enterprises try to proactively implement some improvement activities (Kaizen in Japanese) (Note 2) and decide expected profit as an optimum profit for sustainable growth and competitive strategy by considering the revision and improvement of forecast or estimated profit opportunity and risk (expected loss). For example, when exchange rate, interest rate, or price changes alter enterprise risk, improved profit opportunities are added to the original estimated profit opportunity, while some risk (expected loss) mitigated by the improvement is deducted from the original estimated risk (expected loss). As a result, expected profit is calculated by considering these improvement results on forecast or estimated value for profit opportunity and risk. At the same time, estimated profit is calculated by compiling forecasting based on various factors (data) under present competitive conditions. Moreover, they can recognize forecast profit variance by subtracting estimated profit from expected profit when the latter is larger than the former. After proactively carrying out improvement activities with reference to forecast profit variance, they can acquire the target profit through adding this improved amount to the estimated profit. This target profit becomes a standard to control interim activities and evaluate actual performance. Lost opportunity that is given by its comparison with actual profit becomes an index for this posterior performance evaluation. As a result, this control process leads to the best actualization of business values on the basis of comprehensive profit opportunity and risk management practice.

Although planned profits may be calculated by using quantitative formulations such as linear programming and normal distribution, professional managers' judgment must be adopted in calculating these planned values (see Borison \& Hamm, 2010; Mikes, 2011; Jaafari, 2000). This feed-forward accounting control system is distinguished from the feedback system in comprehensively measuring and controlling multilateral profit opportunities and risks beforehand, in which the forecast ability of management about uncertainty is evaluated beforehand, and actual performance is measured and evaluated from the viewpoint of profit opportunity, risk and lost opportunity (including opportunity cost). At the same time, COLC model can be connected to a cost design model to establish a long-term and more future-oriented cost design. Therefore, lost opportunity or posterior variance can also be recognized in detail in terms of both profit and cost. Target profit leads to allowable cost and target cost is calculated based on this allowable cost, estimated cost and prior cost variance $(=$ prior cost improvement). Here, estimated cost does not to lead to estimated profit but is deduced from the piling up cost and estimated profit. The fundamental structure of the COLC model can be presented in a simple diagram like that below for comparison with the other control models:

\begin{tabular}{|c|c|c|}
\hline \multicolumn{2}{|l|}{ Feed-forward (proactive) accounting control process } & \multirow[b]{2}{*}{$\begin{array}{l}\text { Observed and } \\
\text { variance }\end{array}$} \\
\hline Forecast process and variance analysis & Target & \\
\hline $\begin{array}{l}\text { Forecast profit opportunity- Estimated profit opportunity }=\text { forecast profit opportunity } \\
\text { variance } \\
\text { Forecast risk (expected loss) }- \text { Estimated risk (expected loss) }=\text { forecast risk variance } \\
\text { Forecast profit opportunity }>\text { Estimated profit opportunity } \\
\text { Forecast risk }<\text { Estimated risk } \\
(\text { Estimated profit opportunity }+ \text { improvement }=\text { EOPI) } \\
\text { (Estimated risk - improvement = ERI) } \\
\text { Examination of EOPI and ERI }\end{array}$ & Expected & \\
\hline $\begin{array}{l}\text { Expected profit }- \text { Estimated profit }=\text { Forecast profit variance } \\
\text { Expected profit }>\text { Estimated profit---- }- \text { - } \\
\text { Estimated profit }+ \text { Improvement }=\text { Target profit---- }- \text { Improvement }\end{array}$ & $\begin{array}{l}\text { Target } \\
\text { profit }\end{array}$ & $\begin{array}{l}\text { - Actual profit } \\
\text { = Opportunity } \\
\text { cost variance }\end{array}$ \\
\hline
\end{tabular}

Note. Forecast profit opportunity and risk show planned values from a long-term and sustainable growth viewpoint, while estimated profit opportunity and risk indicate planned values from a short-term and competitive viewpoint; the above assumes that expected loss (risk) increased during the current year. Abbr.: EOPI=Estimated profit opportunity after profit opportunity improvement; ERI=Estimated risk after improvement to mitigate risk. 
This COLC model may seem to be only a theoretical idea, but some Japanese companies focus on opportunity when implementing risk management. Some companies indicate opportunity loss and business opportunities in relation to business risk in their annual securities reports: "There are possibilities of sales-opportunity loss and inventory adjustment that give rise to a confusion of production plans, with the result that an inaccurate forecast of consumer demand and insufficient business management cause excess or short inventories" (Hitachi Manufacturing Company, Annual Securities Report, 2014, p. 12); "The company establishes a system that can smoothly respond to consumer and local needs by appropriately seizing business opportunities when overseas business strategic points develop and promote business strategies" (Sony Corporation, Annual Securities Report, June 2014, p. 28); and "There is a possibility that we will not gain new business opportunities to the extent expected." (Kyosera, Annual Securities Report, 2014, p. 24). The systematization and theorization of these practices plays a critical role in fostering comprehensive and effective enterprise risk management.

\subsection{COLC Model and Its Historical Implication}

As management is strongly aware of uncertainty in business environments, it is proper that greater importance has been attached to feed-forward control information than to the feedback. Thus, risk management is thoroughly colored by feed-forward control information. In the traditional accounting system where past financial data was used for planning and control, uncertainty was ex post facto recognized as the difference between planned and actual values by means of variance analysis. Information on uncertainty was not inserted into control model, because managers convinced themselves that the situation in the future would follow the same trajectory as the present. The planned value was therefore considered a "true cost" (Emerson, 1909; see Scholes, 2000). However, sometimes expectations do not coincide with actual results. For example, managers might not be certain of fluctuations in material prices until price variance was recognized in cost variance analysis after the fact. They use this feedback information to control the changed price in the next period. This, judging from a function over two accounting years, was the feedback control system for uncertainty in the era when managers seemed able to control uncertainty by using such a reactive and reflective management accounting system (Nishimura, 2011).

In the mid-1960s, many managers began to recognize that planned value is relative, rather than absolute, because business conditions are continuously changing. They therefore incorporated un-programmed scenarios into the planning process, adopted alternatives to respond to changing business conditions, and established optimum models for decision-making (Nishimura, 2011). They perceived that value in planning was relative and conditional, and used a known-alternatives model to make optimum decisions. However, uncertainty was not completely controlled. In those days, many quantitative and mathematical models indirectly reinforced accounting control systems for this optimum decision making (Nishimura, 2003). Although accounting control systems were intended to recognize the multifarious changes common to business environments and cope with uncertainty closely related to these changes, there was no system for proactively and preventively controlling uncertainty. Although Demski $(1967,1969)$ introduced the ex post system, in which ex ante profit (the optimum profit before a price change) was compared with ex post profit (the optimum profit after a price change), forecast profit variance was recognized after the measurement of actual profit, and managers' forecasting ability in the planning process was evaluated and controlled from opportunity and opportunity cost by using such an optimum formulation as linear programming and ex post facto variance analysis. This was fundamentally a feedback control system, because this variance could not be measured until actual profit was calculated. However, this consideration of opportunity cost suggested a significant step towards the development of feed-forward control models (Nishimura, 2003). Demski pioneered measuring and evaluating environmental changes and management ability to respond to them from the viewpoints of opportunity and opportunity cost.

Alongside such academic research, under the influence of global market competition some automobile companies in Japan created "cost design" (target costing), which adopts a complete feed-forward process (prior and posterior cost variances that leads to improvement movements) to actualize high-profit opportunities (products at low cost and high quality) with minimum advance risk (zero inventory) (Nishimura, 2003).

As stated above, the present global finance-oriented economy intensifies the uncertainty of the business environment and makes it difficult to ascertain the future direction of business. Mismanagement of uncertainty is not only damaging to the enterprise, but also results in social unease and confusion. Regulatory authorities have therefore required enterprises to strengthen their governance and risk management to protect stakeholders from uncertainty and to secure social stability (Nishimura, 2006). As a result, management accounting, which is closely related to risk management, is also changing its structure and functions, as shown in the COLC model.

Figure 2 shows how the COLC model combines with profit opportunity/risk management and fulfills its function in creating enterprise value and adequately conducting enterprise governance. The transformation of accounting 
information into a comprehensive feed-forward form is given more weight in constructing the COLC model, because business strategy and risk management tends toward strong dependence on proactive information of profit opportunity and risk. The most important function of contemporary management accounting is to recognize and control uncertainty beforehand through profit opportunity and risk management, protecting business from risks and driving it in an advantageous direction through feed-forward methods such as optimal programs, proactive variance analysis, and cost design. The structure of management accounting is also being reorganized, not only from the viewpoint of efficiency and effectiveness, but also from the long-range and global integration of profitability, sustainable growth, and social responsibility. Enterprises must now improve the transparency and trustworthiness of their financial statements and integrate risk management information into them. Additionally, they should use information on variances between profit opportunity and risk and actual accounting income to control business value with proactive efficiency and effectiveness. In this sense, the contemporary accounting control system should adopt a completely feed-forward-oriented system. As a result, an accounting control system strengthens its socio-economic flavor in enterprise risk management as well as environmentally conscious cost design (Nishimura, 2014) through the integration of profitability with social responsibility. As a result of a pivotal junction between risk management and enterprise governance, accounting control systems have become more sensitive to the control of uncertainty than before and have taken on new structures and features.

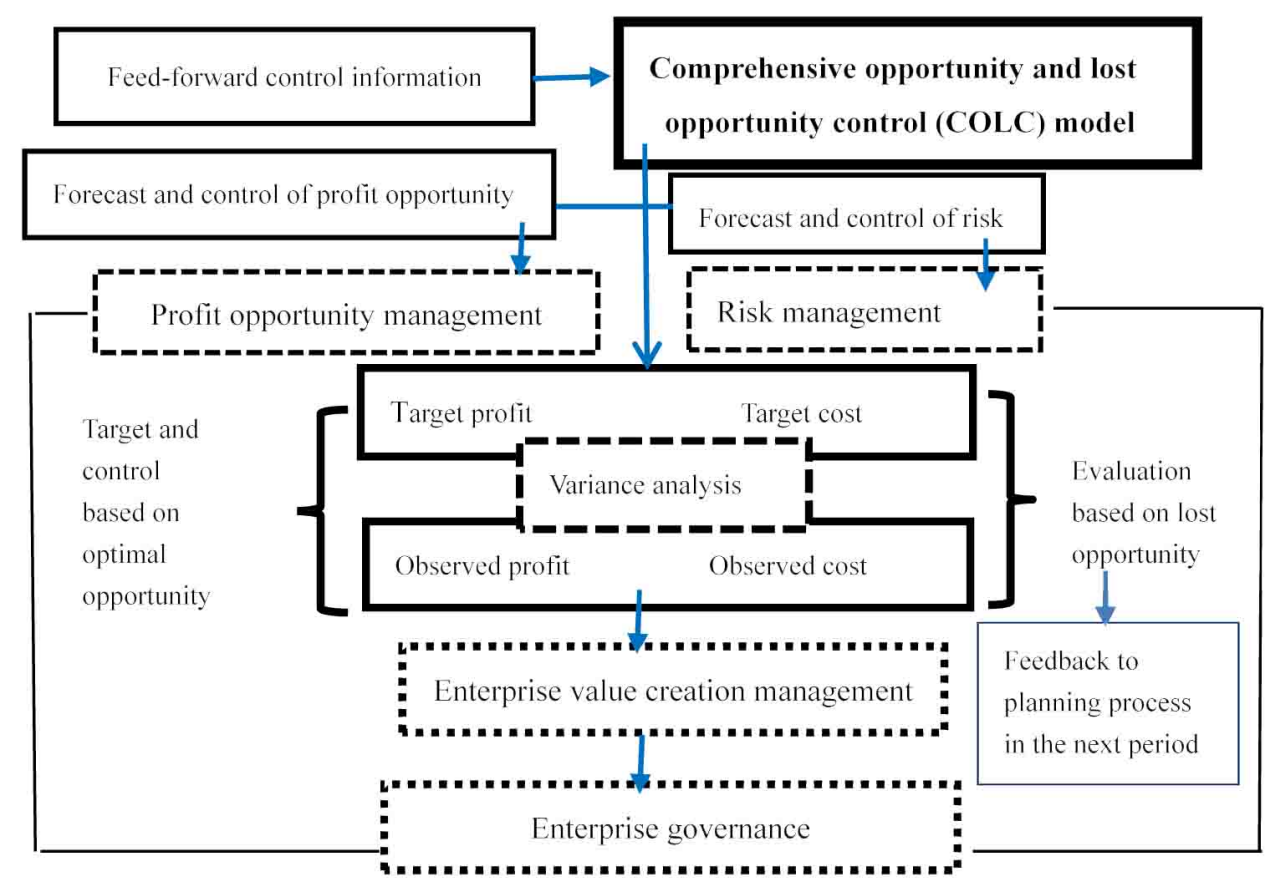

Figure 2. COLC model and enterprise governance

\section{COLC Model and Risk Management Report}

\subsection{Risk Management Report}

Risk strategy and efforts of the whole organization to realize it are fundamental factors in risk management, as failure and carelessness can endanger the value of an enterprise and reduce social confidence in the long term. In more serious cases, this can cause social disaster and economic crisis. In this sense, the evaluation of risk management performance as well as profitability has an important part in organizational efforts to business value creation (Nishimura, 2007). Therefore, an enterprise should give stakeholders a full account of not only indications of risk events that influence its goal but also their management process. This enhances the transparency and social confidence of financial statements.

Although we have described the integrated management of risk and profit opportunity to clarify the role of the COLC model in comprehensive enterprise risk management, a risk management report must further be prepared for the development of socially trustworthy communication in enterprise governance, with reference to this control model. Under the framework of the COLC model, a simple strategic project risk management report can 
be contrived in Table 1.

We can know from the table that this company could attach 36 current profit under 5 remaining risk or evaluate company performance in positive business value creation (36) and risk mitigation effort (115). Moreover, it is necessary to give a full account of the practical meaning of this report in the contemporary business environment.

Table 1. Strategic project risk management report

(31 March 201×) (Units: 100 million yen)

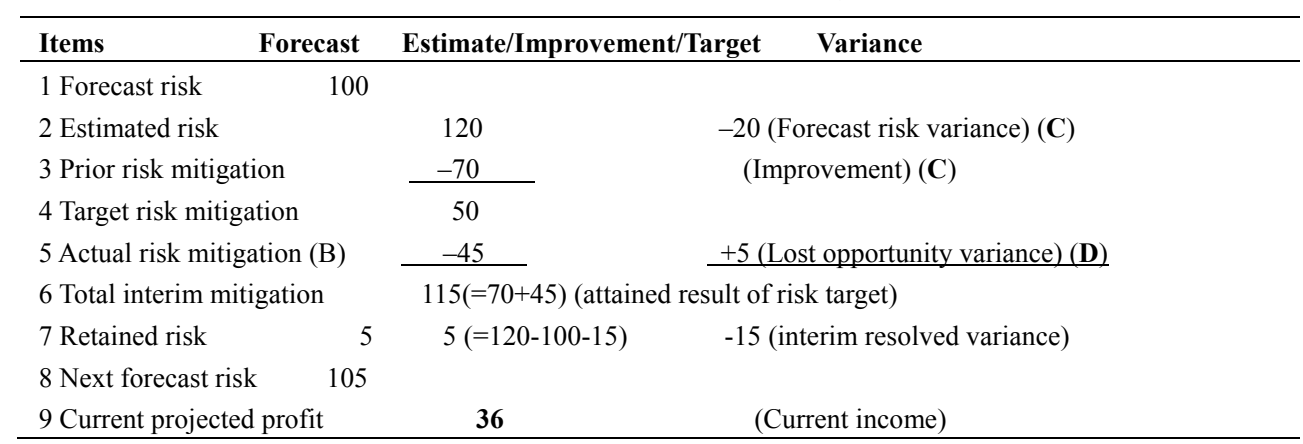

Note. In the above table it is assumed that a company invests 5000 in a project whose payback period is ten years and whose likelihood of risk is $20 \%$. Therefore, forecast risk (expected loss) per year is 100 . There occurred a change in risk probability ( $20 \%$ increase) owing to a supplier problem at planning in this period from the short-term viewpoint. Variance analysis: As for prior risk mitigation, the firm adopted a new proactive countermeasure (change in supply chain) against the 20 and carried out the ready methods beforehand against 100. As a result, 70 risk was mitigated and the company decided 50 as target risk mitigation in this period. It could actualize 45 of the 50 target. As a result there remains 5 risk that must be resolved in the next period; (C) and (D) are on the same line of Figure 1.

With regard to the situation and problems of international financial instrument risk disclosure, Papa and Peters (2011) describe clearly from findings by literature review, direct survey feedback from users of financial statements or respondents to survey questionnaire, and the analysis of IFRS (International Financial Reporting Standards) reporting companies that there, notwithstanding voluminous disclosure, are some problems such as inadequacy of relevant and complete information, difficulty of access, and insufficient understandability and comparability in financial statements. They point out a need "for financial statement preparers to shift away from 'tick-box mere-compliance' with disclosure requirements" and "adopt a meaningful mindset aiming to convey risk exposures and risk management policy effectiveness, as well as to foster a dialogue with investors" (p. 23). Management accountants as well as the statement preparers should be farsighted enough to think of their indication to provide users and society with substantially useful risk information. In this sense, a risk management report needs to be the executive "summary that distills key information on entity-wide risk exposures and effectiveness of risk management practices" across different risk types (Papa \& Peters, 2011, p. $18)$.

\subsection{Risk Management Report and Corporate Accountability}

To clarify the contribution of a feed-forward accounting control system to risk transparency and corporate social responsibility, we inquire into the actual state of risk disclosure by analyzing the financial statements of listed Japanese companies and, for increased improvement of its situation, propose a risk management report to which the COLC model leads.

Table 2 indicates the actual state of risk disclosure in listed Japanese companies, where the average number of risk items per company disclosed by the top 100 Japanese companies by sales amount in fiscal year 2013 is shown. Risk items are divided into four categories according to TRC (2004): strategic, financial, hazard, and operational risk. We can see from Table 2 that generally risks are strongly recognized in connection with strategic planning, managerial and operational control, or the whole management activity, although, in the common situation, commercial companies tend to focus more on financial risk than do other industries, while companies in the electric power, gas, heat supply, and waterworks industries have been very concerned with hazard risks since the Fukushima nuclear power accident and tsunami in March, 2011. This is also confirmed by a comparative analysis of risk items between the 2005 and 2013 fiscal years.

Table 3 presents the difference in risk items in 2005 from those found in fiscal year 2013. We can see that in 
general

corporate risk consciousness has risen since the global financial crisis of 2008. In particular, companies in the mining and information industries have become more sensitive to financial risk, while companies in the electric, gas supply and commercial industries are more sensitive to hazard risk. These changes are influenced by natural and social disasters such as the Great East Japan Earthquake and Tsunami and the Fukushima nuclear disaster of March 2011, but the current tendency of the enhanced risk-disclosure seems to be caused by an amendment of the Company Act in 2006 and the enforcement of the 2009 Financial Instruments and Exchange Act. These laws aim to increase the transparency of financial statements and company compliance through more effective internal control, risk management, and external auditing. The Company Act requires "large companies" (Note 3) to maintain and improve the internal rules that govern their preventive procedures and systems of countermeasures that guard against risk, while the Financial Instruments and Exchange Act puts listed companies under an obligation to prepare internal control reports and external auditing. It also requires them to clearly state the risks of their financial instruments and the risk management systems related to these instruments as notes to the financial statements.

Table 2. The disclosed risk items of top 100 Japanese companies by sales amount: disclosed risk items per company in fiscal year 2013

\begin{tabular}{lcllcc}
\hline Industry (companies, average sales) & Strategic Risk & Financial Risk & Hazard Risk & Operational Risk & Total Risk \\
\hline Mining $(6 ; 1778.3)$ & 5.67 & 1.83 & 1.17 & 1.17 & 9.83 \\
Manufacturing $(55 ; 3835)$ & 9.60 & 2.13 & 1.64 & 3.22 & 16.56 \\
Electric power and Gas; 2893.6) & 6.00 & 1.29 & 3.14 & 3.29 & 13.71 \\
Information $(5 ; 5546.2)$ & 9.80 & 0.80 & 1.60 & 3.60 & 15.80 \\
Transportation $(7 ; 1864.3)$ & 8.86 & 1.29 & 2.00 & 1.71 & 13.86 \\
Commercial $(16 ; 5484.7)$ & 9.06 & 3.13 & 1.81 & 2.38 & 16.38 \\
Others $(4 ; 1625.3)$ & 11.75 & 2.50 & 0.75 & 1.50 & 16.50 \\
Total $(100 ; 3769.3)$ & 9.07 & 2.10 & 1.73 & 2.81 & 15.71 \\
\hline
\end{tabular}

Note. Strategic risk: risks related to business strategy, market and marketing, personnel system, politics, economy, society, media, and capital and liabilities; financial risk: risks related to assets management, settlement of accounts (including changes in interest and exchange rates), and liquidity; hazard risk: risks related to natural disaster, accidents and trouble, and information systems; operational risk: risks related to products and services (including recall and intelligence leakage), legal affairs/ethics, environmental protection, labor management, the management team (including turbulent management and scandals). Source: TRC (2004); EDINET (2005, 2013).

Table 3. Comparison of disclosed risks of top 98 Japanese companies by sales amount between the 2005 and 2013 fiscal years

\begin{tabular}{lccccc}
\hline Industry (company; average sales) & Strategic Risk. & Financial Risk. & Hazard Risk. & Operational Risk. & Total risk \\
\hline Mining (6; 1778.3) & 1.50 & 0.83 & 0.17 & 0.33 & 2.83 \\
Manufacturing (54; 3677) & 1.78 & 0.41 & 0.46 & 0.56 & 3.20 \\
Electric power and Gas $(7 ; 2893.6)$ & 0.71 & 0 & 0.71 & 1.29 & 2.71 \\
Information $(5 ; 5546.2)$ & 1.80 & 0.80 & 0.40 & 1.60 & 4.60 \\
Transportation $(7 ; 1864.3)$ & 2.57 & 0 & 0.29 & 0.29 & 3.14 \\
Commercial $(15 ; 5754.1)$ & 1.87 & 0.07 & 0.87 & 0.87 & 3.67 \\
Others $(4 ; 1625.3)$ & 0.25 & -.0 .25 & 0 & -0.75 & -1.25 \\
Total $(100 ; 3769.3))$ & 1.67 & 0.32 & 0.49 & 0.62 & 3.1 \\
\hline
\end{tabular}

As discussed above, all listed or "large" companies must warn shareholders and stakeholders of risk events. These stakeholders must be aware of corporate risks and at the same time accept investment losses in the near future if strategic and operational activities don't work out or an accident occurs. Moreover, according to Japanese Auditing Standards, external auditors should also conduct an audit of internal control and risk management with "professional skepticism" from the viewpoint of "rationally low auditing risk". Internal control, or the internalized audit (or self-regulation) of business operations that was independent of external accounting audits can be externalized through disputes over corporate governance and risk management. This means that all business activities in these listed companies are inspected by external professional auditors, because of the combination of risk management and business strategy. This externalization is one way to promote good governance, since stakeholders, in particular stockholders, generally have greater confidence in 
external professional auditors than in their own judgment. Is there another way to internalize the "self-regulation" of corporate management and strengthen stakeholders' commitment toward a "participatory democracy" (Drori, 2006 , p. 110)? Is there a positively voluntary way for a company to charge itself with social accountability and controllability?

Although, as indicated in Tables 2 and 3, risk events are increasingly disclosed in financial statements, little is disclosed about how each company plans to manage these risk events. Therefore, stakeholders and society in general cannot know what misfortune will happen in the very near future, or what relation there is between risk and accounting profit, even though this may also be a general trend in other countries (Gates, Nicolas, \& Walker, 2012; see Papa \& Peters, 2011). When risk taking and management processes for dealing with it are not elucidated in financial statements, stockholders and society may feel uneasy maintaining their relation with the company unless they can depend on the opinions of external auditors. At times, investors may wash their hands of the business, and potential investors may wish to stay out of the oncoming disaster, since signs of risk only serve to arouse caution in stakeholders. This seems to be an inducement to the increased social uncertainty.

Most of the surveyed companies did not disclose their risk management process or its result in their financial statements at all. In spite of the upsurge of enterprise risk consciousness, "For a financial institution, a conventional balance sheet does not provide adequate information to insiders or to outsiders such as investors or creditors as to the risk" (Scholes, 2000, p. 18). Even now there may be no dramatic change in this situation for financial or other organizations. If a more general and simpler report based on the "risk management report" (Table 1) (Note 4), or if quantitative information on risk management is included with the internal control report in notes to the financial statements, corporate transparency and social confidence will increase in a small way. As joint-stock companies and disclosure are a product of democracy in modern capitalism, high quality transparency (intelligible and concrete explanations) and accountability (responsibility for quantitative and qualitative substantiation) of the risk management process can not only accelerate "better communication with management" (Gates, Nicolas, \& Walker, 2012), but also become part of the general corporate culture, even to the extent that all listed and "large" companies can keep step with society towards the goal of sustainable growth through "participatory democracy" (Drori, 2006, p. 110), social commitment (see Power, 2007), and criticism. If society becomes sensitive to enterprise risk and these listed companies communicate their corporate and risk management strategies, the conversion of enterprise risk into social risk (or uncertainty) can be moderated (see Heath, Lee, \& Ni, 2009). Business risks may also be reduced or mitigated, as companies can absorb effective ideas from society and improve their management. Society can also examine methods to mitigate the social risks that arise from corporate risks. The choice between greater internalization of "internal risk control" (self-regulation of risk) and its externalization for effective enterprise risk management depends on each nation's political, economic, and social structure. However, even in the former case, management accounting should be reformed to follow not only a more holistic and future-oriented but also socialized and dialogical form.

\section{Conclusion}

Since the financial crisis as symbolized by the globally-linked, finance-oriented economy, and senior managers' abuse of accounting systems, management accounting has become more conscious of uncertainty and its control and has shaped feed-forward accounting control systems to serve enterprise risk management and governance. This has called on accountants and researchers to generalize the relationship between management accounting and risk management (see Bhimani, 2009, p. 2). In this paper a feed-forward accounting control system incorporated profit opportunity and risk information into a proactive and feed-forward control model and made it possible to perform holistic risk management. This paper is intended as a tentative investigation of COLC model and its managerial and social functions. Contemporary accounting control systems should be useful not only for effective risk management, but also for carrying out social and democratic functions through the accountability and disclosure of risk management. However, to achieve this subject enterprises must be strongly conscious of social responsibility and strengthen quality transparency and the voluntary disclosure of risk management, while stakeholders who are concerned with corporate risk management and governance should look to construct a social space in which they can participate and discuss these issues from a variety of viewpoints.

This paper seeks to serve future accounting science by clarifying the feed-forward structure of the COLC model as it shifts from reactive feedback information to proactive feed-forward information and from piecemeal and partially optimum functions to holistic and social functions, corresponding with the holistic perspective of risk management (see Drori, 2006; Power, 2007; Mikes, 2011; Grote, 2014; Rasid, et al., 2014). It also examines the contribution of contemporary management accounting to the control of uncertainty as well as governance in enterprise risk management. 


\section{References}

Abrams, C., Von Kànel, J., Mùller, S., Pfitzmann, B., \& Ruschka-Taylor. (2007). Optimized enterprise risk management. IBM System Journal, 46(2), 219-234.

Arena, M., Arnaboldi, M., \& Azzone, G. (2010). The organizational dynamics of Enterprise Risk Management, Accounting. Organizations and Society, 35(7), 659-675. http://dx.doi.org/10.1016/j.aos.2010.07.003

Arnold, V., Benford, T., Canada, J., \& Sutton, S. G. (2011). The role of strategic enterprise risk management and organizational flexibility in easing new regulatory compliance. International Journal of Accounting Information Systems, 12, 171-188. http://dx.doi.org/10.1016/j.accinf.2011.02.002

Berle, A. A., \& Means, G. C. (1932). Modern Corporation and Private Property. New York: Macmillan.

Bhimani, A. (2009). Risk management, corporate governance and management accounting: Emergence interdependences. Management Accounting Research, 20(1), 2-5. http://dx.doi.org/10.1016/j.mar.2008.11.002

Borison, A., \& Hamm, G. (2010). How to manage risk (after risk management has failed). MIT Sloan Management Review, 51-57.

Clarke, C. J., \& Varma, S. (1999). Strategic risk management: The new competitive edge. Long Range Planning, 32(4), 414-424.

Collins, J. (2009). How the Mighty Fall and Why Some Companies Never Give in. New York: HarperCollins Publishers Inc.

COSO. (2004). Enterprise Risk Management-Integrated Framework: Executive Summary Framework. September, NJ: The Committee of Sponsoring Organizations of the Treadway Commission.

Cushing, B. E. (1968). Some Observations on Demski's Ex Post Accounting System. The Accounting Review, 43(4), 668-671.

Demski, J. S. (1967). An Accounting System Structured on a Linear Programming Model. Accounting Review, 42(4), 701-712.

Demski, J. S. (1968). Some Observations on Demski's Ex Post Accounting System: A Reply. The Accounting Review, 43(4), 672-674.

Demski, J. S. (1969). Decision-performance Control. Accounting Review, 44(4), 669-679.

Demski, J. S. (1977). Analyzing the Effectiveness of the Traditional Standard Cost variance Model. In G. J. Benston (Ed.), Contemporary Cost Accounting and Control (2nd. ed., pp. 222-236). Dickenson Publishing, Inc. California.

Dickinson, G. (2000). Risk role grows to enterprise scale: Enterprise risk management provides control over disparate risks in the business environment. Gerry Dickinson explains how: [Surveys ed.]. Financial Times, 13,8 .

Drori, G. S. (2006). Governed by governance: The new prism for organizational change. In G. S. Drori, J. W. Meyer, \& H. Hwang (Eds.), Globalization and Organization: World Society and Organizational Change (pp. 91-118). New York: Oxford University Press.

Emerson, H. (1909). Efficiency as a Basis for Operation and Wages. Engineering Magazine. New York.

Florricel, S., \& Ibanescu, M. (2008). Using R\&D portfolio management to deal with dynamic risk. $R \& D$ Management, 38(5), 452-467.

Gates, S., Nicolas, J. L., \& Walker, P. L., (2012), Enterprise Risk Management: A process for enhanced management and improved performance. Management Accounting Quarterly, 13(3), 28-38.

Grote, G. (2015). Promoting safety by increasing uncertainty-implications for risk management. Safety Science, 71(part B), 71-79. http://dx.doi.org/10.1016/j.ssci.1014.02.010.

Heath, R. L., Lee, J., \& Ni, L. (2009). Crisis and risk approaches to emergency management planning and communication: The role of similarity and sensitivity. Journal of Public Relations Research, 21(2), 123-141. http://dx.doi.org/10.1080/10627260802557415.

Holmquist, E. (2012). Risk management and business strategy. The RMA Journal, 94(10), 40-45.

IFA. (2004). Enterprise Governance: Getting the Balance Right, booklet prepared by the Professional Accountants in Business Committee (PAIB). New York: International Federation of Accountants (IFA). 
Ingrassia, P. (2011). Crash Course: The American Automobile Industry's Road to Bankruptcy and Bailout—and Beyond. New York: Random House.

Jaafari, A. (2001). Management of risks, uncertainties and opportunities on projects: time for a fundamental shift. International Journal of Project Management, 19, 89-101.

Knight, F. H. (1921). Risk, Uncertainty and Profit, University of Chicago Press: Reprint. Cosimo, Inc. New York.

Leung, F., \& Isaacs, F. (2008). Risk management in public sector research: approach and lessons learned at a national research organization. $R \& D$ Management, 38(5), 510-519.

Mikes, A. (2011). From counting risk to making risk count: Boundary-work in risk management. Accounting, Organizations and Society, 36(4-5), 226-245. http://dx.doi.org/10.1016/j.aos.2011.03.002

Nishimura, A. (2003). Management accounting: Feed-forward and Asian perspectives. Palgrave Macmillan, Hampshire.

Nishimura, A. (2006). Enterprise Governance and Management Accounting from the Viewpoint of Feed-Forward Control. Asia-Pacific Management Accounting Journal, 1(1), 1-17.

Nishimura, A. (2007). Conceptual Analysis of Value-based Management and Accounting: With Reference to Japanese Practices. Asia-Pacific Management Accounting Journal, 2(1), 71-88.

Nishimura, A. (2011). Uncertainty and Management Accounting: Opportunity, Profit Opportunity and Profit. Asia-Pacific Management Accounting Journal, 6(1), 81-101.

Nishimura, A. (2012). Profit Opportunity, Strategic Innovations, and Management Accounting. Asia-Pacific Management Accounting Journal, 7(2), 65-98.

Nishimura, A. (2014). Transforming cost design into environmentally conscious cost design in Japan: Likelihood and problems for further development. Journal of Management Control, 25(1), 55-75. http://dx.doi.org/10.1007/s00187-014-0190-x

Nishimura, A. (2015). Strategic Management Accounting and Feed-Forward Management: With Reference to the Unified Management of Profit Opportunity and Risk. Global Management, 3/4, 4-19.

Papa, V. T., \& Peters, S. J. (2011). User Perspectives on Financial Instrument Risk Disclosures under International Financial Reporting Standards (IFRS). Retrieved from $\mathrm{http} / / /$ www.cfainstitute.org/ethics/Documents/financial_instruments_risk_disclosure_report_volume_1..pdf

Power, M. (2007). Organized Uncertainty: Designing a World of Risk Management. New York: Oxford University Press.

Rasid, S. Z., Isa, C. R., \& Ismail, W. K. W. (2014). Management accounting systems, enterprise risk management and organizational performance in financial institutions. Asian Review of Accounting, 22(2), 128-144. http://dx.doi.org/10.1108/ARA-03-2013-0022

Richardson, J. G. (2009). Uncertainty, the critical basis of risk management. Foresight, 11(6), 42-56, http://dx.doi.org/10.1108/14636680911004957

Richardson, J. G. (2010). The certainty of uncertainty: risk management revisited. Foresight, 12(4), 49-64. http://dx.doi.org/10.1108/14636681011062997

Schneier, R., \& Miccolis, J. (1998). Enterprise risk management. Strategy \& Leadership, 26(2), 10-16.

Scholes, M. S. (2000). Crisis and risk management (the near crash of 1998). The American Economic Review, 90(2), 17-21.

Seal, W. (2006). Management accounting and corporate governance: An institutional interpretation of the agency theory. Management Accounting Research, 17(4), 389-408. http://dx.doi.org/10.1016/j.mar.2006.05.001

Shank, J. K., \& Miguel, J. G. (2009). Merging financial and managerial accounting, strategic cost management and enterprise risk assessment Under SOX. The Journal of Corporate Accounting \& Finance, 83-99. http://dx.doi.org/10.1002/jcaf.20469

Smith, P., G., \& Merritt, G. M. (2002). Proactive Risk Management: Controlling Uncertainty in Product Development. New York: Productivity Press.

Soin, K., \& Collier, P. (2013). Risk and risk management in management accounting and control. Management Accounting Research, 24(2), 82-87. http://dx.doi.org/10.1016/j.mar.2013.04.003 
Stockstrom, C., \& Herstatt, C. (2008). Planning and uncertainty in new product development. $R \& D$ Management, 38(5), 480-490.

Stuart, I., \& Stuart, B. (2004). Ethics in the Post-Enron Age. Cincinnati OH: Thomson South-Western College Pub.

Tanaka, M. (1985). New approach to function evaluation system in value engineering. International Journal of Production Research, 23(4), 625-638.

Tanaka, M. (1995). Theory and Practices of Cost Design. Chuo-keizaisha Publisher, Co. Tokyo.

Tanaka, T. (1992). Field-Study: Contemporary Management Accounting System. Chuo-keizaisha Publisher, Co. Tokyo.

Tang, O., Matsukawa, H., \& Nakashima, K. (2012). Supply chain risk management. International Journal of production Economics, 139(1), 1-2. http://dx.doi.org/10.1016/j.ijpe.2012.06.015.

TRC. (2004). The Definitive and Digestible Book on Risk Management: the newest version. Tokyo: Tokio Marine Risk Consulting, Co. Ltd.

\section{Notes}

Note 1. A holistic approach is one that assesses, explores, monitors, and controls risks from all sources of an organization in more integrated and comprehensive manner than do piecemeal approaches (Leung and Isaacs, 2008; Clarke \& Varma, 1999; See also Stockstrom \& Herstatt, 2008; Abrams, et al. 2007).

Note 2. Improvement is used as an inclusive means that shows ameliorative and alternative response to profit opportunity and risk variances. Concretely, it clears up their factors and causes, and takes measures to raise the probability of profit opportunities and to lower the risk likelihood. The situation of strategic innovations is modified or altered for profit opportunities, while avoidance (such as buying insurance), compensation (agreement) or dissolution (cooperation) is considered for risk. At the same time, organizational structure and opportunity/risk consciousness among constituents in the organization must be improved, and risks must be kept from triggering risks in other areas. (Dickinson, 2000; COSO, 2004; Clarke \& Varma, 1999; Leung \& Issacs, 2008; Arena, Arnaboldi \& Azzone, 2010). Although Kaizen in Japanese means activities which inspect and reexamine all product factors and production process for improvement of quality and cost, here it takes in a broader sense including the reexamination of strategy and innovation process.

Note 3. Here, "large companies" means companies whose capital stock is more than 500 million yen and whose liabilities are more than 20 billion yen. For details about the Company Act, the Financial Instruments and Exchange Act, and auditing standards in Japan, see "regulations" in Data and Materials from Websites.

Note 4. The "risk management report" is only one example of high-quality transparency. More exhaustive and easy-to understand reports will have to be contrived. Moreover, it may be more useful if the entity-wide risk exposures are classified into large groups: strategic risk, financial instrument risk, and operational activity risk.

\section{Copyrights}

Copyright for this article is retained by the author(s), with first publication rights granted to the journal.

This is an open-access article distributed under the terms and conditions of the Creative Commons Attribution license (http://creativecommons.org/licenses/by/3.0/). 